\title{
SEQÜÊNCIA DOS ESTUDOS \\ SOBRE A PRODUÇÃO EXPERIMENTAL DE MEGASSÍNDROMES EM CAMUNDONGOS
}

\author{
Vania A. Soares, Maurício P. Gama, Nelson J. Alvarenga e Philip D. Marsden
}

\begin{abstract}
A capacidade de produção de megassindrome de três cepas de Trypanosoma cruzi de diferentes origens foram examinadas usando-se técnicas previamente descritas. Uma correlação significante foi encontrada entre volume e peso do estômago através de autópsia e a área correspondente a silhueta de bário do órgão. Todas as três cepas causam dilatação significante da área do estômago, após prolongada infecção em camundongos quando comparados com o grupo controle não infectado. Todavia, o modelo de comportamento da cepa (MEGA), previamente estudada, pode ter sido alterada pela reciclagem em camundongos nos laboratórios.
\end{abstract}

Palavras chaves: Doença de Chagas. Megassíndrome experimental.

Recentemente demonstrou-se que cepas de Trypanosoma cruzi, isoladas de pacientes apresentando megaesôfago, puderam produzir megaestômago em camundongos após cerca de 1 ano de infecção ${ }^{1}$. Megaestômago pode ser detectado em animais vivos por contraste de bário, sendo que não se detectou ocorrência de megaesôfago ou megacólon nos animais infectados, nem mesmo pela autópsia, embora estes animais apresentassem uma sensível demora de tempo no trânsito intestinal, quando comparados com animais normais.

No sentido de estender essas observações, investigou-se a capacidade de produção de "Megas" a partir de cepas de diferentes origens, bem como seu comportamento em comparação com uma das cepas utilizadas no trabalho citado acima.

Foram feitas observaçōes sobre a acuidade do método de medida do perfil radiográfico do estômago como medida alternativa e válida do volume deste mesmo órgão.

\section{MATERIAL E MÉTODOS}

Cepas utilizadas: Mega B - isolada de um paciente proveniente da Bahia apresentando megaesôfago Grau III. Esta cepa sabidamente produziu megaestômago em camundongos crônicos após 1

Universidade de Brasília

Centro de Pesquisas René Rachou

Núcleo de Medicina Tropical - Caixa Postal 153121 -

Brasília-DF ano de infeç̧ão; $\mathrm{K}$ - isolada de um exemplar adulto de Panstrongylus megistus doméstico capturado em Catolândia, Bahia; Unaí - isolada de um caso agudo da Doença de Chagas, proveniente de Unaí, Minas Gerais. Todas as cepas têm sido mantidas em laboratórios por passagens cíclicas em camundongos, e até o momento de sua utilização apresentavam o seguinte número de passagens: Mega B, 2; K, 14 e Unaí 7. O desenvolvimento do experimento foi semelhante aquele descrito em trabalho anterior (Marsden et al, 1979); lotes de 50 camundongos fêmeas jovens, tipo suíço $\mathrm{n}$ ? 40 , foram inoculadas com um número conhecido de tripomastigotas sangüineos de cada cepa de $T$. cruzi. Sendo: Mega B, 7.800 formas; Cepa K, 9.100 formas e Cepa Unaí 26.000 formas. Os camundongos que não apresentaram parasitemia patente em exames de gota de sangue aos 14,21 e 28 dias foram excluídos. Alvarenga e Marsden (1975) demonstraram que $95 \%$ dos animais inoculados apresentavam-se positivos dentro deste período. Aqueles positivos para cepa Unai foram autopsiados aos 267 dias e os infectados pelas cepas "K" e "Mega B" aos 427 dias de infecção assim como um grupo de 50 camundongos não infectados mantidos em condições semelhantes (grupo controle). Observou-se durante o experimento, uma mortalidade de $40 \%$, tanto nos grupos infectados (K, Mega e Unaí) quanto nos controles. Dois dias antes da autópsia a ração foi retirada e somente 24 horas antes foi dada aos animais uma mistura de ração e bário. Os camundongos anestesiados eram radiografados (Marsden et al, 1979). Em seguida os perfis dos estômagos eram desenhados em papéis padronizados que eram pesados. Na autópsia fo- 
Soares VA, Gama MP, Alvarenga NJ, Marsden PD. Seqüência dos estudos sobre a produçāo experimental de megassíndromes em camundongos. Revista da Sociedade Brasileira de Medicina Tropical 16:148-153, Jul/Set, 1983

ram tomadas as dimensões das várias partes do in. testino e estômago, sendo esse último pesado em balança Sartorius $(0,01 \mathrm{mg})$; em seguida imerso em uma proveta graduada em $0,1 \mathrm{~cm}^{3}$, com água e seu volume foi medido pelo deslocamento do líquido. Fragmentos do estômago, junção esofageal, intestino delgado e grosso, coração e músculo esquelético foram fixados em formol a $10 \%$ para exame anatomo-patológico.

A análise estatística dos dados consistiu na determinação do grau de dependência entre o peso do perfil e o volume do estômago. $O$ coeficiente de Pearson foi utilizado, testando-se, também, para cada valor obtido, a hipótese de nulidade. Para as variáveis que apresentaram maior coeficiente de correlação foram calculadas as equações de regressão, utilizando-se a variável peso do perfil como dependente. Nos casos em que o coeficiente de correlação foi maior de 0,50 , utilizou-se a equação de regressão para, com base na variável dependente, estimar-se o valor das variáveis independentes (volume e peso do estômago).

Testou-se, ainda, através da análise de variància, a hipótese de igualdade das médias. Nos casos em que o teste (TESTE " $F$ ") indicou diferença, identificou-se esta diferença através do teste de Duncan (1). Todos os testes foram realizados a um nivel de significância de $\alpha=0,05(\mathrm{p}<$ $0,05)$.

\section{RESULTADOS}

Tabela 1 - Estudo da Correlaçāo entre as variáveis PP-Peso do Perfil, PE-Peso do Estômago, VE-Volume do Estômago.

Valores do Coeficiente de Correlaçāo

\begin{tabular}{|c|c|c|c|c|c|c|}
\hline & \multicolumn{3}{|c|}{ Controle $(N=13)$} & \multicolumn{3}{|c|}{$\operatorname{Unai}(N=16)$} \\
\hline & $P P$ & $P E$ & $V E$ & $P P$ & $P E$ & $V E$ \\
\hline $\mathrm{PP}$ & 1 & 0.6176 & 0.4873 & 1 & 0.7486 & 0.7630 \\
\hline PE & & 1 & 0.9676 & & 1 & 0.9077 \\
\hline \multirow[t]{3}{*}{ VE } & & & 1 & & & 1 \\
\hline & \multicolumn{3}{|c|}{$K \quad(N=13)$} & \multicolumn{3}{|c|}{ Mega $\quad(N=11)$} \\
\hline & $P P$ & $P E$ & $V E$ & $P P$ & $P E$ & $V E$ \\
\hline PP & 1 & 0.6856 & 0.7336 & 1 & 0.2893 & 0.0222 \\
\hline $\mathrm{PE}$ & & 1 & 0.8899 & & 1 & 0.7646 \\
\hline $\mathrm{VE}$ & & & 1 & & & 1 \\
\hline
\end{tabular}

O teste da hipótese de nulidade do coeficiente de correlação foi rejeitado em quase todos casos com exceção do grupo MEGA onde os valores de $r=0.2893$ e $r=0.0222$ tiveram aceita a hipótese de nulidade respectivamente com $\mathrm{P}>0.194$ e $\mathrm{P}>$
01479. Podemos concluir que, neste grupo, há independênçia entre o volume do estômago (VE) e o peso do perfil (PP) e este com o peso do estômago (PE). 
Soares VA, Gama MP, Alvarenga NJ, Marsden PD. Seqüência dos estudos sobre a produção experimental de megassíndromes em camundongos. Revista da Sociedade Brasileira de Medicina Tropical 16:148-153, Jul/Set, 1983

Tabela 2 - Comparação entre as médias observadas para os diversos grupos. Análise da Variância.

\begin{tabular}{|c|c|c|c|c|c|c|c|}
\hline \multirow{2}{*}{ Grupo } & \multicolumn{2}{|c|}{ Peso do Perfil } & \multicolumn{2}{|c|}{ Peso Estômago } & \multicolumn{2}{|c|}{ Vol. Estômago } & \multirow{2}{*}{$\begin{array}{l}\text { Tamanho } \\
\text { Amostra }\end{array}$} \\
\hline & Média & $\begin{array}{l}\text { Desvio } \\
\text { Padrão }\end{array}$ & Média & $\begin{array}{l}\text { Desvio } \\
\text { Padrão }\end{array}$ & Média & $\begin{array}{l}\text { Desvio } \\
\text { Padrão }\end{array}$ & \\
\hline Controle & 0,059 & 0,015 & 1,005 & 0,307 & 1,062 & 0,343 & 13 \\
\hline Unaí & 0,105 & 0,029 & 1,509 & 0,356 & 2,725 & 0,800 & 16 \\
\hline $\mathrm{K}$ & 0,097 & 0,018 & 0,282 & 0,528 & 2,318 & 0,876 & 11 \\
\hline Niega & 0,097 & 0,024 & 1,317 & 0,432 & 2,123 & 0,855 & 11 \\
\hline
\end{tabular}

O resultado da análise da variância evidenciou que há diferença significante entre as médias das variáveis calculadas para cada um dos grupos.
Para localização da diferença entre as médias utilizou-se o teste de Duncan, cujos resultados são apresentados abaixo:

Tabela 3 - Volume do Estômago - Contrastes - Teste de Duncan

\begin{tabular}{lccccc}
\hline & Médias & Unai & $K$ & Mega & Controle \\
\cline { 3 - 6 } Médias & & 2,725 & 2,318 & 2,123 & 1,062 \\
\hline Controle & 1,062 & $1,633^{* *}$ & $1,256^{* *}$ & $1,061^{* *}$ & - \\
Mega & 2,123 & 0,602 & 0,195 & - & - \\
K & 2,318 & 0,407 & - & - & - \\
Unaí & 7,725 & - & - & - & - \\
\hline
\end{tabular}

Todas as médias foram iguais entre os grupos: Unaí, K e MEGA, obtendo-se diferença de ca- da uma das médias quando comparadas com o grupo controle.

Tabela 4 - Peso do Estômago - Contrastes - Teste de Duncan

\begin{tabular}{lccccc}
\hline & Médias & Unai & $K$ & Mega & Controle \\
\cline { 3 - 6 } Médias & & 1,509 & 1,317 & 1,282 & 1,005 \\
\hline Controle & 1,005 & $0,504^{* *}$ & $0,312^{* *}$ & $0,272^{* *}$ & - \\
K & 1,282 & 0,227 & 0,035 & - & - \\
Mega & 1,317 & 0,192 & - & - & - \\
Unai & 0,509 & - & - & - & - \\
\hline
\end{tabular}

Com exceção da constatação de diferença entre o grupo controle e os grupos Unaí e Mega, nas demais comparações foi aceita a igualdade entre as médias. 
Soares VA, Gama MP, Alvarenga NJ, Marsden PD. Seqüência dos estudos sobre a produçāo experimental de megassíndromes em camundongos. Revista da Sociedade Brasileira de Medicina Tropical 16:148-153, Jul/Set, 1983

Tabela 5 - Peso do Perfil - Contrastes - Teste de Duncan

\begin{tabular}{lccccc}
\hline & Médias & Unai & $K$ & Mega & Controle \\
\cline { 3 - 6 } Médias & & 0,105 & 0,097 & 0,097 & 0,059 \\
\hline Controle & 0,059 & $0,046^{* *}$ & $0,038^{* *}$ & $0,038^{* *}$ & - \\
Mega & 0,097 & 0,008 & - & - & - \\
K & 0,097 & 0,008 & - & - & - \\
Unaí & 0,105 & - & - & - & - \\
\hline
\end{tabular}

Todas as médias foram iguais, entre os grupos: Unai, $\mathrm{K}$ e MEGA, obtendo-se a diferença quando testada contra o grupo controle.

Retas de regressão

Tabela 6 - Peso do Perfil como função do Volume do Estômago $P P=f(V E)$

\begin{tabular}{lllllll}
\hline \multicolumn{1}{c}{ Grupo } & \multicolumn{1}{c}{ Equaçōes } & $\begin{array}{l}\text { Coef. de } \\
\text { determi- } \\
\text { nação }\end{array}$ & $F$ & Conclusão & \multicolumn{1}{c}{$\begin{array}{l}\text { DF. graus de } \\
\text { liberdade }\end{array}$} \\
\hline Controle & $\mathrm{PP}=0,0292+0,02958 \mathrm{VE}$ & 0,38183 & 6,79455 & Há regressão & $(1,11)$ \\
Unaí & $\mathrm{PP}=0,01205+0,06146 \mathrm{VE}$ & 0,56046 & 17,85144 & Há regressão & $(1,14)$ \\
$\mathrm{K}$ & $\mathrm{PP}=0,06588+0,2392 \mathrm{VE}$ & 0,47004 & 7,98253 & Há regressão & $(1,9)$ \\
Mega & $\mathrm{PP}=0,7648+0,01579 \mathrm{VE}$ & 0,08372 & 0,82231 & N há regressão & $(1,9)$ \\
\hline
\end{tabular}

Retas de regressão

Tabela 7 - Peso do Perfil como função do Peso do Estômago $P P=f(P E)$

\begin{tabular}{lcccccc}
\hline Grupo & Equaçōes & $\begin{array}{l}\text { Coef. de } \\
\text { determi- } \\
\text { nação }\end{array}$ & $F$ & Conclusão & $\begin{array}{l}\text { DF graus de } \\
\text { Liberdade }\end{array}$ \\
\hline Controle & $\mathrm{PP}=0,03736+0,0208 \mathrm{PE}$ & 0,23746 & 3,42542 & $\tilde{\mathrm{N}}$ há regressão & $(1,11)$ \\
Unaí & $\mathrm{PP}=0,02876+0,0279 \mathrm{PE}$ & 0,58224 & 19,51205 & Há regressão & $(1,14)$ \\
$\mathrm{K}$ & $\mathrm{PP}=0,06076+0,1544 \mathrm{PE}$ & 0,53864 & 10,49996 & Há regressão & $(1,9)$ \\
Mega & -- & -- & -- & - & -- \\
\hline
\end{tabular}

A análise do coeficiente de determinação mostra que, para a relação $P P=f(V E)$, somente o grupo Unaí apresenta um grau de explicação suficientemente alto para permitir a utilização do modelo regressivo. Para a relação $P P=f(P E) o$ grau de explicação foi alto para as cepas Unaí e K. Nestes três casos é possivel a utilização das equações para, dado o peso do perfil, estimar-se o volume e peso do estômago. 
Soares VA, Gama MP, Alvarenga NJ, Marsden PD. Seqüência dos estudos sobre a produção experimental de megassíndromes em camundongos. Revista da Sociedade Brasileira de Medicina Tropical 16:148-153, Jul/Set, 1983

\section{ESTIMATIVA DO VOLUME \\ DO ESTOMAGO ATRAVÉS DO PESO DO PERFIL}

\section{Grupo Unaí}

A equação para estimar-se o VE será:

$$
\begin{gathered}
\mathrm{VE}=\frac{\mathrm{PP}-0,01205}{0,06146} \\
\text { DO ESTIMATIVA DO PESO } \\
\text { PESO DO PERFIL }
\end{gathered}
$$

Cepas Unaí e K

As equações são respectivamente:

$$
\begin{array}{ll}
\hline P E=\frac{P P-0,02876}{0,0279} & \text { para Unaí } \\
P E=\frac{P P-0,06076}{0,1544} & \text { para } K
\end{array}
$$

\section{DISCUSSÃO}

Em três dos quatro grupos estudados foi realizado o teste de nulidade para o coeficiente de correlação de Pearson. No caso da cepa Mega B a correlação foi nula, possivelmente por ser a amostra pequena; eventualmente, aumentando-se o tamanho da amostra a hipótese de nulidade será rejeitada.

Os estudos de Regressão mostraram-se válidos no caso das cepas K e Unaí. Quanto aos estudos comparativos das 3 medidas nos 4 grupos de camundongos ( 3 infectados com $T$. cruzi) houve uma diferença significante para a variável volume do estômago quando comparada com o grupo controle. Isto foi válido para o volume e o peso do perfil do estômago. As diferenças não foram tão claras no caso da medida direta do peso do estômago, mas nesse caso entra um novo fator, o bário residual presente no órgão, que pode explicar o resultado obtido.
A pouca diferença observada no volume dos esțômagos dos roedores nas cepas Unaí e Mega $\mathrm{B}$, a diferença do tempo de incubação assim como a diferença de origens, sugerem que será difícil demonstrar por este modelo uma diferença clara na capacidade das cepas em produzir megas.

Além disso, a cepa Mega B não mostrou os mesmos resultados do experimento anterior (Marsden et al, 1979), o que poderia ser explicado pela perda da capacidade de produzir dilatação no estômago através de repicagens sucessivas. Será importante, portanto, o uso de cepas recém-isoladas e um número adequado de camundongos isogênicos nas próximas séries de experiências, onde serão comparadas diretamente cepas com capacidade de produzir cardiopatias e megas no homem.

O estudo da capacidade de produção de mega nas 3 cepas de $T$. cruzi, de origens diferentes, mostrou que todas causam dilatação significante no estômago de camundongos depois de incubação prolongada neste hospedeiro, embora megaestômago marcante não tenha sido demonstrado como em trabalho anterior, para uma cepa (Mega), utilizando-se a mesma técnica. A análise estatística (Regressão Linear) mostrou haver diferença significativa nos resultados desta cepa em relação às demais.

\section{SUMMARY}

The mega-producing capacity of three strains of Trypanosoma cruzi of widely different origins was examined using techniques previously described. A significant correlation was found for two of the strains between the volume and weight of the stomach at autopsy and measurement of the area of a barium silhouette of this organ.

All three strains caused significant stomach dilatation after prolonged infection in the mice when compare with a control uninfected group. However the behavior of a strain (mega) previously studied in this model had altered, possibly as a result of repeated mice passage in the laboratory.

Key words: Chagas' disease. Experimental megasyndrome.

\section{AGRADECIMENTO}

Queremos expressar nossos agradecimentos ao Conselho Nacional de Desenvolvimento Cienti- 
Soares VA, Gama MP, Alvarenga NJ, Marsden PD. Seqüência dos estudos sobre a produção experimental de megassíndromes em camundongos. Revista da Sociedade Brasileira de Medicina Tropical 16:148-153, Jul/Set, 1983

fico e Tecnológico $(\mathrm{CNPq})$, pelos recursos financeiros.

\section{REFERĒNCIA}

1. Marsden PD, Alvarenga NJ, Soares VA, Gama MP.
Attempts to Produce Megasyndrome in Mice using stocks of Trypanosoma cruzi Associated with Mega oesophagus in man Transations Royal Society of Tropical Medicine and Hygiene. 73:651-655, 1979. 